\title{
PERENCANAAN JUMLAH TOLL GATE
}

\author{
Muhammad Zainul Arifin ${ }^{* 1}$, Devina Candra Puspita Rini ${ }^{2}$, Khairul Arifin², \\ Ludfi Djakfar ${ }^{1}$ \\ ${ }^{1}$ Dosen, Fakultas Teknik, Universitas Brawijaya \\ 2 Alumni, Fakultas Teknik, Universitas Brawijaya \\ *Korespondensi: mzaub@ub.ac.id
}

\begin{abstract}
Pasuruan-Probolinggo toll road was built to increase economic sector in East Java Region. Prior to construction, it's necessary to analyze potential of toll road users and planning the ideal number of toll gates to comply with minimum service standards. This study uses Stated Preference method to determine vehicle switch, planning of ideal toll gates using Poisson Distribution, and FIFO queuing model used to analyze toll gate service system. Based on analysis, the largest potential road users who will switch to use PasuruanProbolinggo toll road section IV in 2021, 2025, 2030, 2035, and 2040 are 5,49\%, 23,84\%, 30,63\%, 30,63\%, and 30,63\%. The calculation of toll gates is adjusted to the calculation of potential toll road users in 2025, 2030, 2035, and 2040 with the arrival of 385, 503, 657, and 858 vehicles/hour/strip. So, the ideal number of toll gates needed in 2025-2030, are 4 units, and 2035-2040 are 8 units of toll gates.
\end{abstract}

Keywords: Stated Preference, potential toll users, queue model, toll gates.

\section{PENDAHULUAN}

Wilayah Kota/Kabupaten Pasuruan dan Probolinggo merupakan salah satu wilayah yang menjadi pusat distribusi barang dalam sektor perdagangan dan industri di Provinsi Jawa Timur. Padatnya aktivitas pergerakan menyebabkan padatnya arus lalu lintas pada jalan nasional (Pantura). Sehingga, kemacetan yang terjadi memiliki dampak tersendiri bagi penyedia barang karena menyebabkan naiknya harga produksi. Untuk mengurangi permasalahan di atas, maka dilakukanlah pembangunan jalan tol Pasuruan-Probolinggo yang terdiri dari empat seksi. Pada penelitian ini difokuskan pada jalan tol Pasuruan-Probolinggo seksi IV yang masih dalam tahap pembangunan. Sebelum melakukan pembangunan lebih lanjut, diperlukan analisis untuk mengetahui besarnya potensi pengguna jalan yang berpindah dari jalan eksisting ke jalan tol serta diperlukan juga perhitungan jumlah gardu ideal yang dibutuhkan agar sesuai dengan Standar Pelayanan Minimum (SPM) yang berlaku. Sebagai contoh seperti yang dilansir pada laman Ekonomi \& Bisnis.com pada Juni tahun 2019 lalu, bahwa jalan tol trans jawa di Batang, Jawa Tengah mengalami kenaikan jumlah kendaraan yang tidak diimbangi dengan jumlah gardu tol yang ideal, yang menyebabkan panjang antrian mencapai lebih dari $3 \mathrm{~km}$ [1]. Pradana, dkk. [2] dalam penelitiannya tentang kebutuhan gardu tol Cikande Bahwa pada volume kendaraan tertinggi sebanyak 2037 kendaraan, sedangkan jumlah kendaraan yang beralih ke jalan tol sebanyak 15438 kendaraan/hari dan jumlah gardu tol sebanyak lima buah gardu tol. Sedangkan Wasistha [3], dalam penelitiannya tentang perencanaan jumlah gerbang tol Pandaan-Malang dengan menggunakan metode First In First Out sebagai disiplin antrian dan metode Single Channel-Single Phase untuk struktur antrian pada gerbang tol.

\section{TINJAUAN PUSTAKA}

Berdasarkan Undang-Undang Republik Indonesia Nomor 38 tahun 2004 tentang jalan, sistem jaringan jalan merupakan satu kesatuan ruas jalan yang saling menghubungkan dan mengikat pusat-pusat pertumbuhan dengan wilayah yang berada dalam pengaruh pelayanannya dalam satu hubungan yang hierarkis. Sedangkan jalan tol adalah jalan 
umum yang merupakan bagian dari sistem jaringan jalan dan sebagai jalan nasional yang penggunanya diwajibkan untuk membayar tol.

\subsection{Stated Preference (SP)}

Metode ini merupakan sebuah metode yang bertujuan untuk mengetahui besarnya perpindahan moda dengan cara mengubah persepsi pengguna jalan menjadi skala probabilitas. Skala probabilitas yang sudah didapatkan kemudian diolah menjadi skala simetrik agar dapat ditransformasikan menjadi nilai utilitas. Sebelum mengolah data stated preference, responden diberikan preferensi untuk memilih antara $\mathrm{X}$ dan $\mathrm{Y}$ yang direntangkan pada bentuk pilihan 1-5, yang mana:

1 = pasti memilih $\mathrm{X}$

2 = mungkin memilih $\mathrm{X}$

3 = mungkin memilih salah satunya

4 = mungkin memilih $\mathrm{Y}$

5 = pasti memilih $\mathrm{Y}$

Skala yang sudah disebutkan kemudian ditransformasikan ke dalam bentuk probabilitas (Berkson Theil Transformation) dengan ketentuan:

$1=0,9$

$2=0,7$

$3=0,5$

$4=0,3$

$5=0,1$

Kemudian nilai probabilitas tersebut ditransformasikan menjadi skala simetrik agar berubah menjadi nilai utilitas yang dapat ditentukan dengan rumus sebagai berikut:

$$
\text { Utilitas } \operatorname{Ln}=P /(1-P)
$$

Analisis data Stated Preference menggunakan metode regresi [4]. Analisis metode ini dibutuhkan untuk memperoleh hubungan secara kuantitatif antara kumpulan atribut dengan respon setiap individu. Model yang dihasilkan akan membentuk pola hubungan antara variabel bebas dengan terikat. Regresi linier yang digunakan berupa persamaan yang menggunakan satu atau lebih variabel bebas. Bentuk umum yang digunakan untuk peramalan merupakan hubungan linier antara variabel bebas (X) dan variabel terikat (Y) sebagai berikut:

$Y=a_{0}+a_{1}\left(X_{1}\right)+a_{2}\left(X_{2}\right)+a_{t}\left(X_{t}\right)$

dimana,

$\mathrm{Y}=$ respon individu

$$
\begin{array}{ll}
\mathrm{a}_{0} & =\text { konstanta } \\
\mathrm{X}_{1}, \mathrm{X}_{2}, \mathrm{X}_{\mathrm{t}} & =\text { atribut pelayanan } \\
\mathrm{a}_{1}, \mathrm{a}_{2}, \mathrm{a}_{\mathrm{t}} & =\text { mungkin memilih } \mathrm{Y}
\end{array}
$$

\subsection{Model Logit Biner/Binomial}

Model ini merupakan model yang sering dan mudah digunakan. Bentuk permodelan berupa probabilitas (\%) peluang moda i yang dipilih bergantung pada parameter kepuasan dalam menggunakan moda $i$ dan moda $j$ serta nilai eksponensial.

$P_{M 1}=\frac{e^{U M 1}}{e^{U M 1}+e^{U M 2}}=\frac{e^{\left(U M_{1}-U M_{2}\right)}}{1+e^{\left(U M_{1}-U M_{2}\right)}}$
$P_{M 2}=1-P M_{1}=\frac{1}{1+e^{\left(U M_{1}-U M_{2}\right)}}$

dimana,

PM1 = probabilitas penggunaan moda 1

PM2 = probabilitas penggunaan moda 2 UM1

$=$ fungsi utilitas moda 1

$\mathrm{UM} 2$ = fungsi utilitas moda 2

\subsection{Perencanaan Jumlah Gardu Tol}

Dalam perencanaan kebutuhan gardu mengacu pada peraturan [5]. Data yang diperlukan dalam merencanakan jumlah gardu tol yaitu:

1. Volume Lalu lintas

2. Waktu pelayanan

3. Standar pelayanan

Untuk menghitung jumlah gardu yang dibutuhkan, langkah-langkah yang dilakukan adalah sebagai berikut :

1. Menghitung Volume Jam Rencana:

$V J R=V L H R x \frac{K}{100}$

2. Menghitung tingkat pelayanan rata-rata gardu:

$\mu=\frac{1 \mathrm{jam}}{\text { Waktu pelayanan }}$

3. Menghitung jumlah gardu:

$\rho=\frac{\lambda / N}{\mu}$

dimana,

$\mathrm{k} \quad=11 \%$ (untuk jalan bebas hambatan)

$\rho=$ perbandingan kedatangan dengan

tingkat pelayanan gardu

$\lambda \quad=$ volume jam perencanaan

$\mu \quad=$ tingkat pelayanan rata-rata 
4. Menghitung sistem pelayanan gardu (menggunakan metode antrian FIFO) [4] :

$\bar{n}=\frac{\lambda / N}{\mu-(\lambda / N)}$

$\bar{q}=\frac{(\lambda / N)^{2}}{\mu(\mu-(\lambda / N))}$

$\bar{d}=\frac{1}{(\mu-\lambda / N)} \times 3600$

$\bar{w}=\frac{(\lambda / N)}{\mu(\mu-(\lambda / N))} \times 3600$

dimana,

$\bar{n}=$ jumlah rata-rata kendaraan dalam sistem (kendaraan/satuan waktu).

$\bar{q}=$ jumlah rata-rata kendaraan dalam antrian (kendaraan/satuan waktu).

$\bar{d}=$ waktu rata-rata kendaraan dalam sistem (satuan waktu).

$\bar{w}=$ waktu rata-rata kendaraan dalam antrian (satuan waktu).

\section{METODE PENELITIAN}

Kerangka pemikiran yang dijadikan sebagai dasar dalam memudahkan proses analisis studi digambarkan secara sistematis agar penelitian yang dilakukan menjadi terarah. Berikut ini disajikan diagram kerangka pemikiran dari penelitian yang dijelaskan pada Gambar 1.

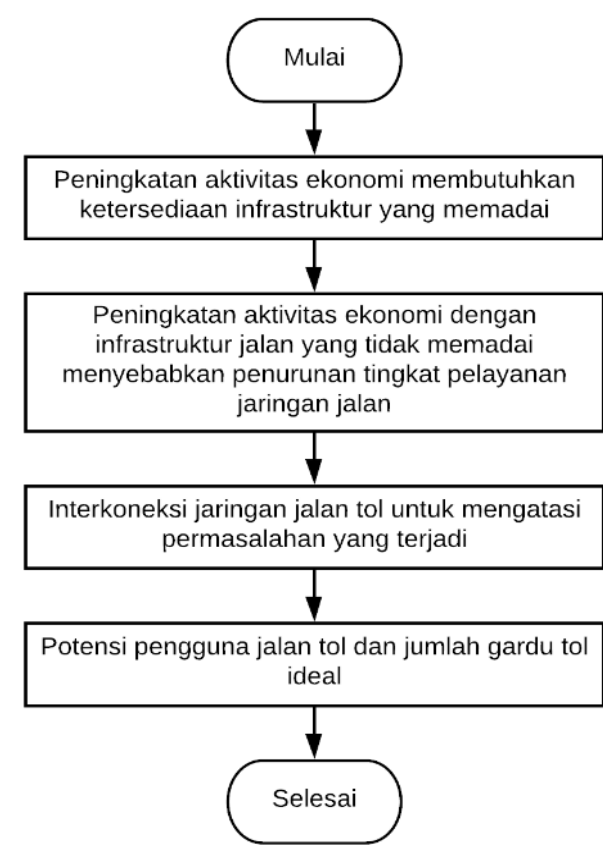

Gambar 1. Kerangka Pemikiran

\subsection{Diagram Alir Penelitian}

Diagram alir penelitian merupakan sebuah konsep dasar dalam pelaksanaan penelitian yang disusun dengan sistematis. Diagram alir penelitian dapat dilihat pada Gambar 2. 

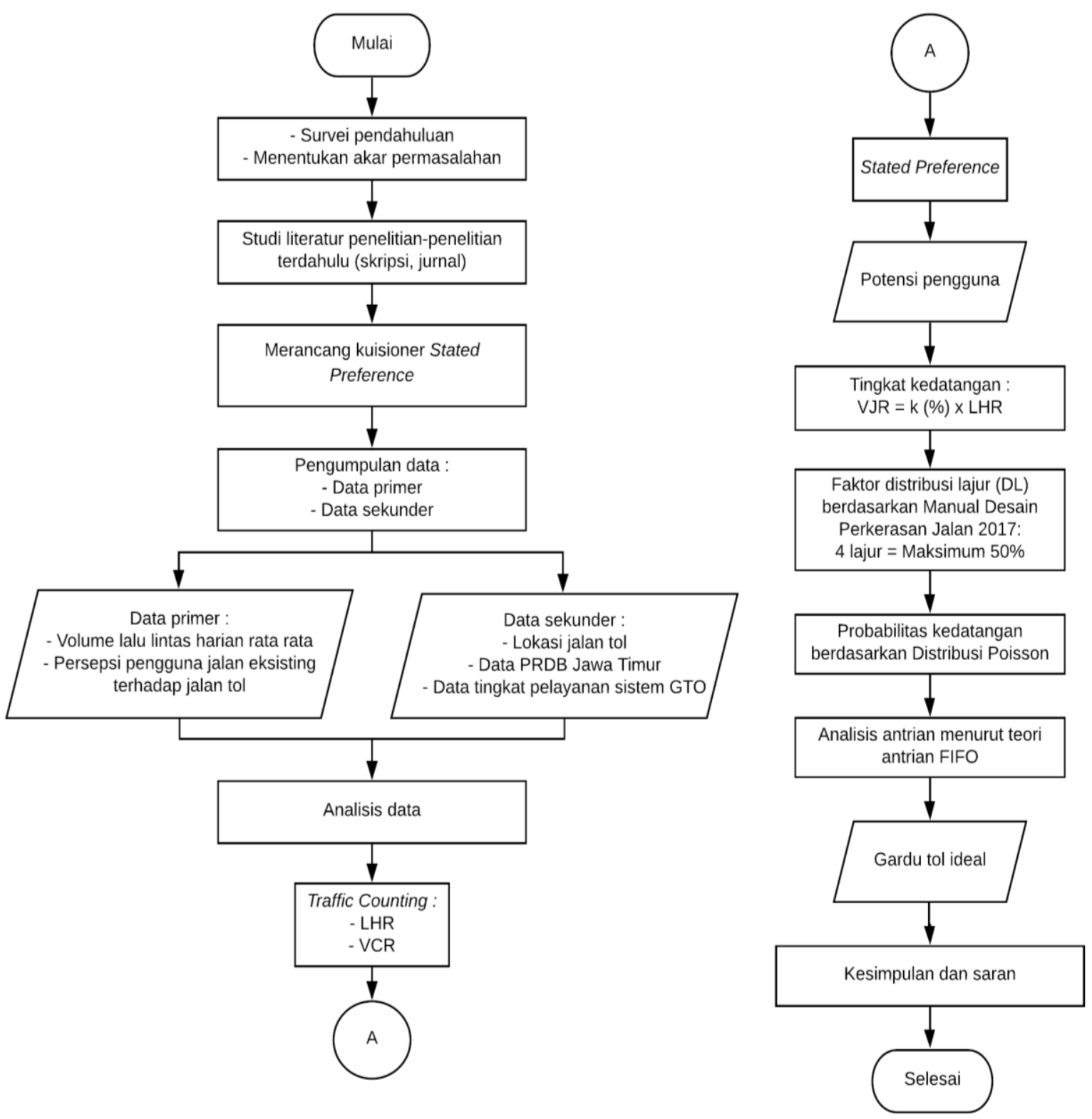

Gambar 2. Diagram Alir Penelitian

\subsection{Penetapan Sampel}

Jumlah sampel yang ditetapkan menggunakan pendekatan rumus Slovin:

$n=\frac{N}{1+N \cdot d^{2}}$

dimana,

$\mathrm{N} \quad=$ jumlah lalu lintas harian rata-rata (sumber: survei Traffic Counting)

$\mathrm{d}=0,05$ (untuk tingkat ketelitian data $95 \%)$

\subsection{Tempat Survei Wawancara}

Survei Stated Preference dilakukan dengan metode Road Side Interview. Lokasi survei dilakukan di area SPBU Jalan SoekarnoHatta Kota Probolinggo, SPBU Leces, Rest Area Tongas Alun-alun Kota Probolinggo, dan SPBU di sepanjang Jalan Raya Gending.

\section{HASIL DAN PEMBAHASAN \\ 4.1 Data Traffic Counting}

Data Traffic Counting diperoleh dari perhitungan volume lalu lintas di daerah lokasi studi. Data Traffic Counting dapat dilihat pada Tabel 1. 
Tabel 1. Rekapitulasi Data Traffic Counting Jl. Raya Gending

\begin{tabular}{cccc}
\hline \multicolumn{4}{c}{ LHR } \\
\hline Jenis & \multicolumn{3}{c}{ Hari Ke } \\
\cline { 2 - 4 } Kendaraan & $\mathbf{1}$ & $\mathbf{2}$ & $\mathbf{3}$ \\
\hline GOL I & 12610 & 12645 & 13100 \\
\hline GOL II & 2792 & 2683 & 3249 \\
\hline GOL III & 593 & 617 & 669 \\
\hline GOL IV & 77 & 69 & 90 \\
\hline GOL V & 193 & 184 & 172 \\
\hline GOL VI & 28216 & 22119 & 25590 \\
\hline
\end{tabular}

\subsection{Data Sebaran Responden Stated Preference}

Data yang diperlukan untuk analisis Stated Preference adalah data persepsi pengguna jalan terhadap jalan tol. Data sebaran responden dapat dilihat pada Tabel 2.

Tabel 2. Rekapitulasi Sebaran Responden ATPWTP dan Stated Preference

\begin{tabular}{cccccc}
\hline \multirow{2}{*}{ Lokasi } & \multicolumn{5}{c}{ Golongan } \\
\cline { 2 - 5 } & I & II & III & IV & V \\
\hline Rest Area Tongas & 6 & 2 & 0 & 0 & 0 \\
\hline Alun-alun Probolinggo & 9 & 0 & 0 & 0 & 0 \\
\hline Terminal Bayu Angga & 30 & 0 & 0 & 0 & 0 \\
\hline $\begin{array}{c}\text { SPBU Jl. Soekarno- } \\
\text { Hatta }\end{array}$ & 45 & 11 & 2 & 0 & 0 \\
\hline SPBU Leces & 61 & 25 & 3 & 0 & 0 \\
\hline SPBU Gending & 152 & 38 & 9 & 2 & 4 \\
\hline Jumlah & 303 & 75 & 16 & 2 & 4 \\
\hline
\end{tabular}

\subsection{Analisis Stated Preferences}

Dalam analisis ini, ditampilkan 2 atribut pilihan, yaitu VCR dan tarif tol/km yang akan digunakan sebagai bahan pertimbangan bagi responden dalam memilih untuk beralih menggunakan jalan tol atau tetap menggunakan jalan eksisting. Jumlah responden dapat dilihat pada Tabel 3.

Data skala pilihan yang sudah direkap kemudian diubah dalam bentuk skala probabilitas (P). Kemudian data yang dimasukkan merupakan data yang sudah diubah ke dalam bentuk utilitas sebagai variabel terikat sedangkan data tarif dan VCR sebagai variabel bebas.
Tabel 3. Jumlah Responden Stated Preference

\begin{tabular}{cc}
\hline $\begin{array}{c}\text { Golongan } \\
\text { Kendaraan }\end{array}$ & Jumlah \\
\hline I & 303 \\
\hline II & 75 \\
\hline III & 16 \\
\hline IV & 2 \\
\hline V & 4 \\
\hline Total & 400 \\
\hline
\end{tabular}

Tabel 4. Hasil Analisis Regresi Linier Ganda Untuk Kendaraan Golongan I

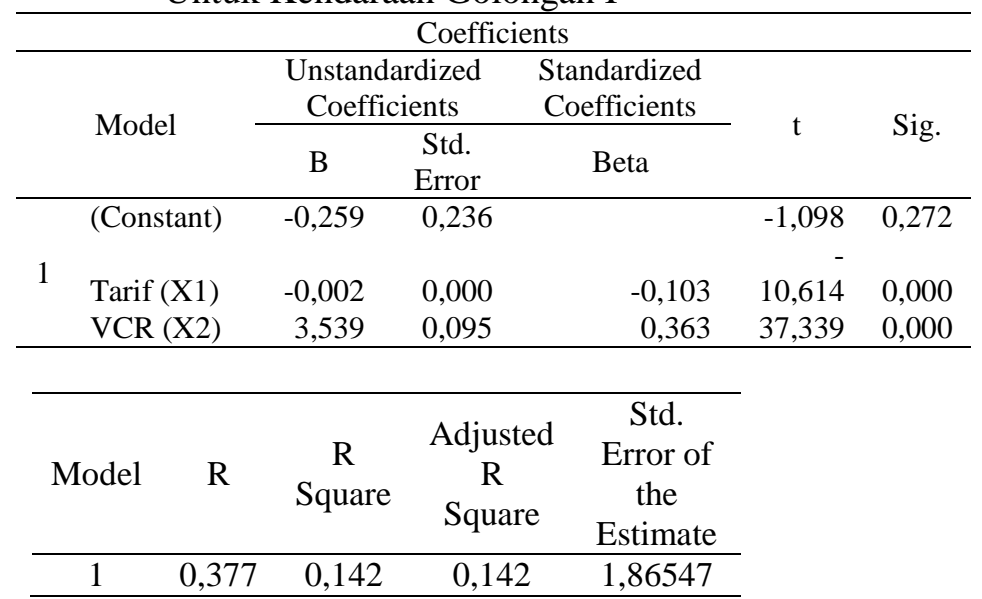

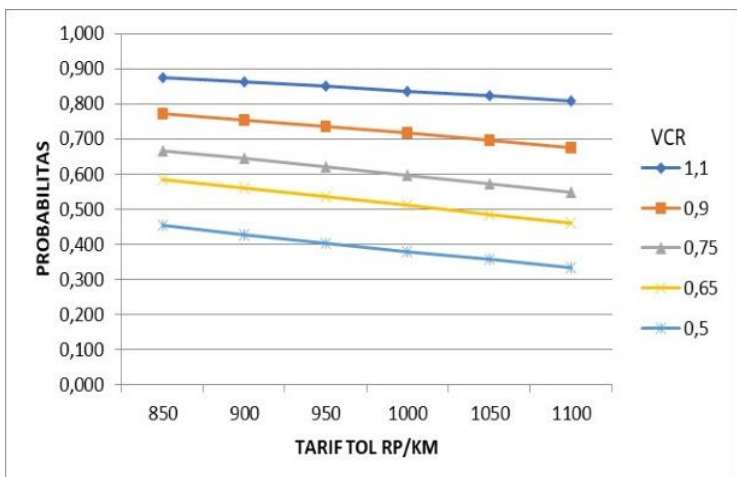

Gambar 3. Probabilitas pengguna jalan tol dan jalan eksisting PasuruanProbolinggo golongan I 
Tabel 5. Hasil Analisis Regresi Lnier Ganda Untuk Kendaraan Golongan II

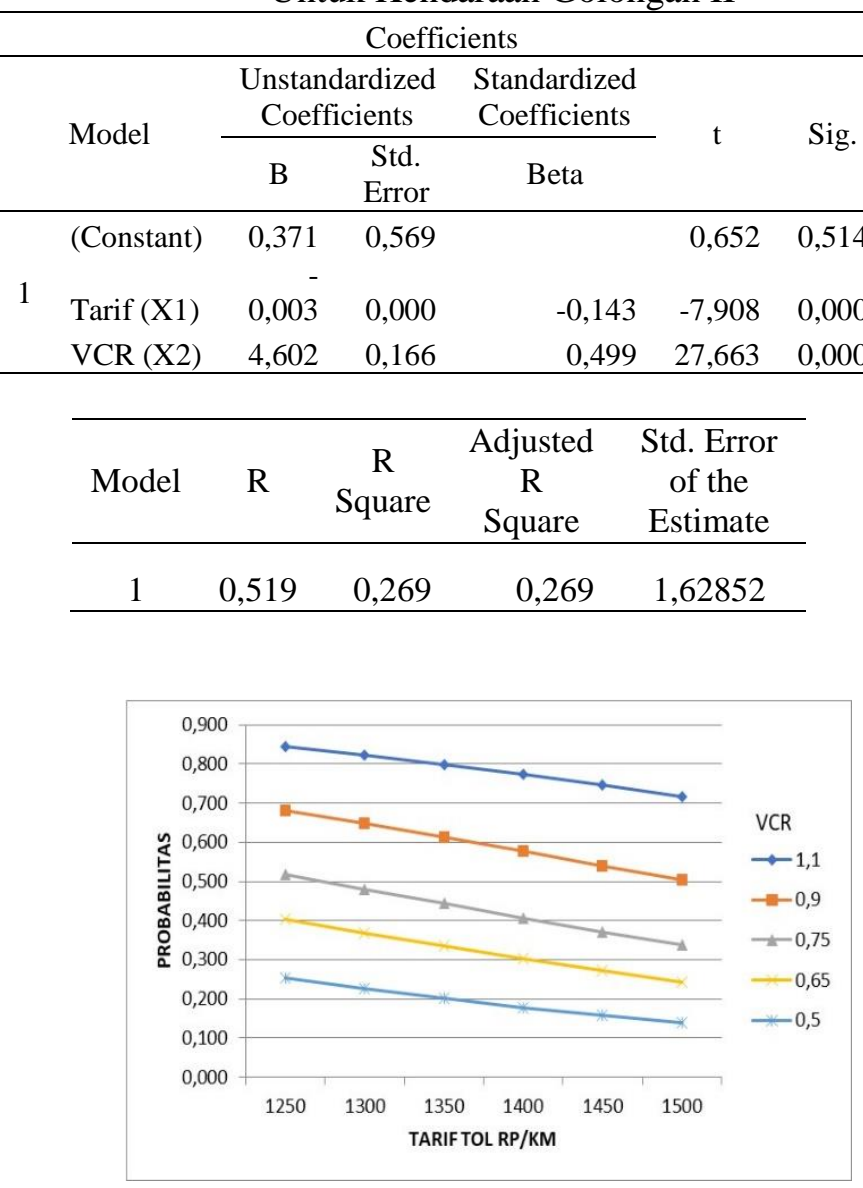

Gambar 4. Grafik Probabilitas Pengguna Jalan Tol dan Jalan Eksisting PasuruanProbolinggo Golongan II

Tabel 6. Hasil analisis regresi linier ganda untuk kendaraan golongan III Coefficients

\begin{tabular}{|c|c|c|c|c|c|c|}
\hline & \multirow{2}{*}{ Model } & \multicolumn{2}{|c|}{$\begin{array}{c}\text { Unstandardized } \\
\text { Coefficients }\end{array}$} & \multirow{2}{*}{$\begin{array}{c}\begin{array}{c}\text { Standardized } \\
\text { Coefficients }\end{array} \\
\text { Beta }\end{array}$} & \multirow{2}{*}{$\mathrm{t}$} & \multirow{2}{*}{ Sig. } \\
\hline & & B & $\begin{array}{l}\text { Std. } \\
\text { Error }\end{array}$ & & & \\
\hline \multirow{3}{*}{1} & (Constant) & 1,393 & 1,03 & & $-1,352$ & 177 \\
\hline & Tarif (X1) & 0,002 & 0,001 & $-0,111$ & $-3,225$ & 0,001 \\
\hline & $\operatorname{VCR}(\mathrm{X} 2)$ & 5,288 & 0,282 & 0,648 & 18,762 & 0,000 \\
\hline
\end{tabular}

\begin{tabular}{ccrrc}
\hline Model & $\mathrm{R}$ & $\begin{array}{c}\mathrm{R} \\
\text { Square }\end{array}$ & $\begin{array}{c}\text { Adjusted } \\
\mathrm{R} \\
\text { Square }\end{array}$ & $\begin{array}{c}\text { Std. Error of } \\
\text { the Estimate }\end{array}$ \\
\hline 1 & 0,657 & 0,432 & 0,429 & 1,27445 \\
\hline
\end{tabular}

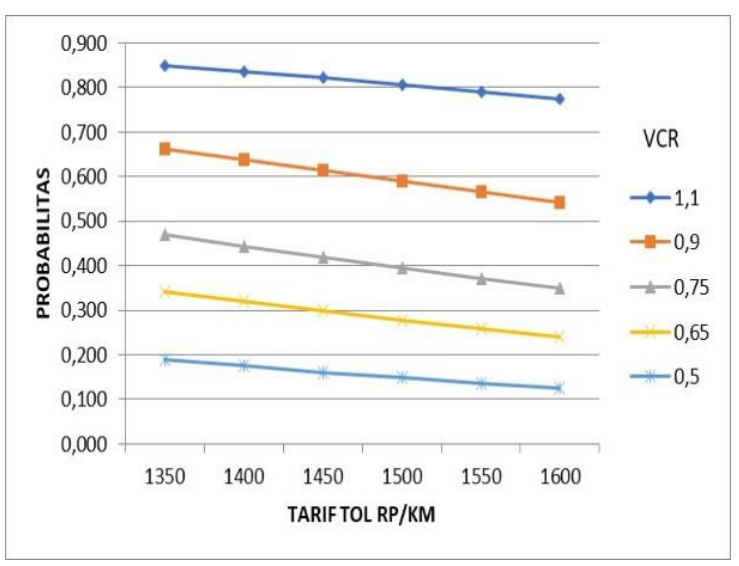

Gambar 5. Grafik Probabilitas Pengguna Jalan Tol dan Jalan Eksisting PasuruanProbolinggo golongan III

\subsection{Analisis Potensi Pengguna Jalan Tol Pasuruan-Probolinggo Seksi IV}

Potensi pengguna diperoleh dengan cara mengalikan hasil probabilitas yang diperoleh dari model logit binomial dengan volume kendaraan yang melalui jalan eksisting. Volume kendaraan yang digunakan adalah hasil dari Traffic Counting (TC) selama jam puncak pada setiap ruas jalan sekitar tol PasuruanProbolinggo seksi IV, sebagaimana ditunjukkan pada Tabel 7 [6].

Tabel 7. Volume Kendaraan Total Pada Jalan Eksisting Sekitar Tol PasuruanProbolinggo

\begin{tabular}{cccc}
\hline & I & II & III \\
\cline { 2 - 3 } GOLONGAN & \multicolumn{3}{c}{$\begin{array}{l}\text { Volume Kendaraan } \\
\text { (Kendaraan/hari) }\end{array}$} \\
\cline { 2 - 3 } & 13073 & 3249 & 669 \\
\hline
\end{tabular}

Untuk perencanaan potensi pengguna, menggunakan nilai VCR sebesar 0,75 karena pada kondisi ini kenyamanan dari pengguna jalan sudah mulai terganggu karena arus lalu lintas yang mulai tidak stabil dan termasuk ke dalam LOS (Level of Service) D. Dengan demikian, potensi kendaraan dari masingmasing golongan kendaraan dapat diperoleh dengan cara mengalikan jumlah LHR dengan nilai PJT nya, seperti yang tertera pada Tabel 8 [6]. 
Tabel 8. Potensi Kendaraan Berdasarkan LHR dan VCR

\begin{tabular}{cccc} 
GOLONGAN & LHR & PJT & POTENSI \\
\hline I & 13073 & 0.667 & 8721 \\
\hline II & 3249 & 0.518 & 1683 \\
\hline III & 669 & 0.468 & 313
\end{tabular}

\subsection{Prediksi Pengguna Jalan Tol Pasuruan- Probolinggo pada Masa Mendatang}

Proyeksi pertumbuhan jumlah pengguna jalan diperlukan dalam penyusunan rencana pembangunan jalan tol sebagai pertimbangan apakah proyek tersebut layak untuk dilakukan atau tidak. Data dan nilai pertumbuhan jumlah kendaraan bermotor, PDRB dan penduduk di daerah Jawa Timur per tahun 2014-2019), diperlihatkan dalam Tabel 9 [7]. Dari data tingkat pertumbuhan, maka dapat dianalisis potensi pengguna jalan tol PasuruanProbolinggo seksi IV seperti yang dapat dilihat pada Tabel 10.

Tabel 9. Pertumbuhan PDRB dan Penduduk Provinsi Jawa Timur

\begin{tabular}{ccccc}
\hline & \multicolumn{5}{c}{ Data } \\
\cline { 2 - 5 } Tahun & PDRB & Penduduk & PDRB & Penduduk \\
& & & \\
\hline $\mathbf{2 0 1 4}$ & 1262,68 & 38610292 & \\
\hline $\mathbf{2 0 1 5}$ & 1331,39 & 38784300 & $5,44 \%$ & $0,45 \%$ \\
\hline $\mathbf{2 0 1 6}$ & 1405,56 & 39041400 & $5,57 \%$ & $0,66 \%$ \\
\hline $\mathbf{2 0 1 7}$ & 1482,15 & 39287300 & $5,45 \%$ & $0,63 \%$ \\
\hline $\mathbf{2 0 1 8}$ & 1563,76 & 39521900 & $5,51 \%$ & $0,60 \%$ \\
\hline $\mathbf{2 0 1 9}$ & 1650,14 & 39698000 & $5,52 \%$ & $0,45 \%$ \\
\hline \multicolumn{6}{c}{ Rata-rata pertumbuhan } & $\mathbf{5 , 4 9 \%}$ & $\mathbf{0 , 5 9 \%}$ \\
\hline
\end{tabular}

Dengan menggunakan rumus

$F=P \times(F / P ; i ; n)$

dimana,

$\mathrm{F} \quad=$ potensi pengguna tol pada tahun $\mathrm{x}$

$\mathrm{P} \quad=$ potensi pengguna tol pada saat ini

( 8721; 1683; 313)

$\mathrm{i} \quad=$ laju pertumbuhan (Faktor PDRB)

$\mathrm{n} \quad=$ jumlah tahun
Maka hasil perhitungan potensi pengguna jalan tol Pasuruan-Probolinggo seksi IV dapat diketahui seperti yang dapat dilihat pada Tabel 10.

Tabel 10. Potensi Pengguna Jalan Tol Pasuruan-Probolinggo Seksi IV Pada Masa Mendatang

\begin{tabular}{cccc}
\multirow{2}{*}{ Tahun } & \multicolumn{3}{c}{ Golongan } \\
\cline { 2 - 4 } & I & II & III \\
\hline $\mathbf{2 0 2 1}$ & 9200 & 1776 & 330 \\
\hline $\mathbf{2 0 2 5}$ & 11393 & 2199 & 409 \\
\hline $\mathbf{2 0 3 0}$ & 14883 & 2873 & 535 \\
\hline $\mathbf{2 0 3 5}$ & 19443 & 3753 & 698 \\
\hline $\mathbf{2 0 4 0}$ & 25399 & 4902 & 912 \\
\hline
\end{tabular}

\subsection{Perencanaan Jumlah Gardu Tol}

Perhitungan yang dibutuhkan terdiri dari nilai tingkat kedatangan rata-rata kendaraan per lajur, sehingga digunakan rumus VJR (Volume Jam Rencana) yang dapat dihitung dengan rumus (5). Hasil perhitungan dapat dilihat pada Tabel 11.

Tabel 11. Perhitungan Tingkat Kedatangan Rata-rata Kendaraan

\begin{tabular}{ccccc}
\hline \multicolumn{1}{c}{ Tahun } & $\mathbf{2 0 2 5}$ & $\mathbf{2 0 3 0}$ & $\mathbf{2 0 3 5}$ & $\mathbf{2 0 4 0}$ \\
\hline $\begin{array}{l}\text { Jumlah LHR } \\
\text { (kend/jam) }\end{array}$ & 14001 & 18291 & 23894 & 31214 \\
\hline $\mathbf{k}$ & \multicolumn{4}{c}{0.11} \\
\hline $\begin{array}{l}\text { VJR ( } \boldsymbol{\lambda}) \\
\text { (kend/jam/lajur) }\end{array}$ & 385 & 503 & 657 & 858 \\
\hline
\end{tabular}

Berdasarkan Manual Desain Perkerasan Jalan (2017), faktor distribusi lajur (DL) untuk jalan dengan 4 lajur adalah maksimum sebesar $50 \%$ dari total kendaraan dalam lajur yang sama. Maka, direncanakan jumlah gardu sebanyak 2 buah di setiap lajurnya. Sehingga, jumlah total gardu yang direncanakan sebanyak 8 buah. Setelah itu menghitung tingkat pelayanan ratarata dengan rumus (6). Lalu dengan distribusi poisson menghitung kapasitas gardu dengan rumus (7). Maka, dapat dihitung juga indikasi yang digunakan untuk menilai sistem pelayanan. Hasil perhitungan dapat dilihat pada Tabel 12. 


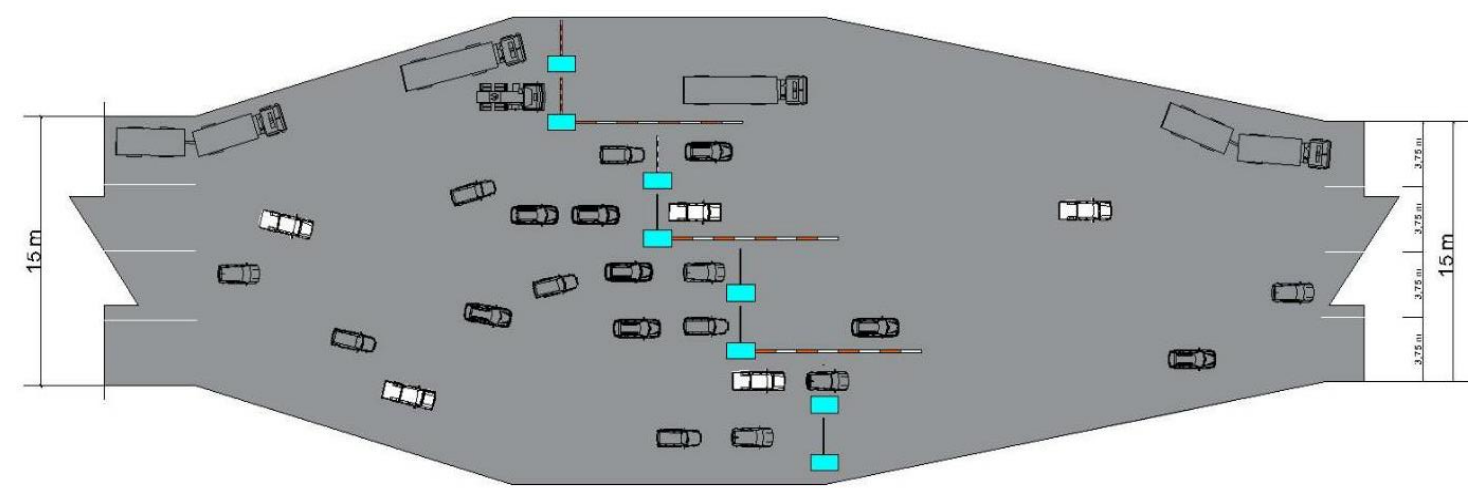

Gambar 6. Layout Antrian Gardu Tol

Tabel 12. Jumlah Gardu Ideal dan Sistem Pelayanannya

\begin{tabular}{ccccc} 
& \multicolumn{4}{c}{ Tahun } \\
\cline { 2 - 5 } Sistem & \multicolumn{4}{c}{ Jumlah Gardu } \\
\cline { 2 - 5 } Pelayanan & $\mathbf{2 0 2 5}$ & $\mathbf{2 0 3 0}$ & $\mathbf{2 0 3 5}$ & $\mathbf{2 0 4 0}$ \\
\cline { 2 - 5 } & $\mathbf{4}$ & $\mathbf{4}$ & $\mathbf{8}$ & $\mathbf{8}$ \\
\hline $\bar{n}$ & 1.98 & 6.56 & 1.31 & 2.85 \\
\hline $\bar{q}$ & 1.31 & 5.69 & 0.74 & 2.11 \\
\hline $\bar{d}$ & 18.49 & 46.93 & 14.33 & 23.92 \\
\hline $\bar{w}$ & 12.28 & 40.72 & 8.12 & 17.71
\end{tabular}

Untuk perencanaan digunakan gerbang dengan tipe barrier yaitu tipe gerbang yang terletak pada jalur utama dengan susunan gardu semi paralel, seperti yang terlihat pada Gambar 6.

\section{KESIMPULAN DAN SARAN}

\subsection{Kesimpulan}

Menurut hasil analisis didapatkan beberapa kesimpulan seperti berikut:

1. Potensi pengguna jalan tol PasuruanProbolinggo seksi IV pada masa mendatang dianalisis untuk tahun 2021, 2025, 2030, 2035, dan 2040 adalah sebesar 5,49\%, $23,84 \%, 30,63 \%, 30,63 \%$, dan $30,63 \%$, dimana potensi pengguna jalan terbesar yang akan beralih menggunakan jalan tol Pasuruan-Probolinggo secara berturut-turut untuk kendaraan golongan I adalah 9200, 11393, 14883, 19443, dan 25399 kendaraan/hari; potensi kendaraaan golongan II adalah sebesar 1776, 2199, 2837, 3753, dan 4902 kendaraan/hari; potensi kendaraaan golongan III adalah sebesar 330, 409, 535, 698, dan 912 kendaraan/hari.

2. Perhitungan jumlah gardu tol disesuaikan dengan perhitungan potensi pengguna jalan tol Pasuruan-Probolinggo seksi IV pada tahun 2025, 2030, 2035, dan 2040 dengan tingkat kedatangan kendaraan 385, 503, 657, dan 858 kendaraan/jam/lajur. Maka, jumlah gardu tol yang diperlukan pada tahun 20252030 sebanyak 4 buah, dan tahun 2035, sampai dengan 2040 sebanyak 8 buah gardo tol

\subsection{Saran}

Saran yang dapat diberikan untuk perbaikan dan penyempurnaan pada penelitian mengenai perencanaan jumlah gardu tol agar diperoleh hasil yang lebih optimal dengan pelaksanaan yang lebih efektif dan efisien, yaitu sebagai berikut:

1. Karakteristik lokasi studi harus dipahami dengan baik. Jika waktu penelitian memakan waktu yang lama, maka harus sering melalukan survei agar dapat mengetahui perubahan atau perkembangan yang dapat mempengaruhi penelitian pada lokasi studi.

2. Data sekunder yang diperlukan dalam penelitian sebaiknya menggunakan data terbaru agar hasilnya lebih akurat. 
3. Data traffic counting disarankan menggunakan data 24 jam agar mewakilii seluruh pergerakan yang terjadi pada lokasi studi.

\section{DAFTAR PUSTAKA}

[1] Ekonomi \& Bisnis.com , 2019, Pengguna Jalan Tol Batang-Semarang Meningkat Signifikan https://ekonomi.bisnis.com/read/20190608/4 5/931692/

[2] Pradana, M. Fakhruriza., Intari, Dwi Esti., \& Kurniawan, Febri. (2017). Perencanaan Ulang Kebutuhan Gardu Tol Pada Gerbang Tol Cikande. Jurnal Fondasi Universitas Sultan Ageng Tirtayasa.

[3] Wasistha, Magistra Zuhair (2017) Perencanaan Gerbang Tol Pandaan-Malang.
Undergraduate thesis, Institut Teknologi Sepuluh Nopember

[4] Siagian,P. 1987. Penelitian Operasional : Teori dan Praktek. Universitas Indonesia Press. Jakarta.

[5] Departemen Pekerjaan Umum Direktorat Jenderal Bina Marga. Standar Konstruksi dan Bangunan No 007/BM/2009 tentang Geometri Jalan Bebas Hambatan Untuk Jalan Tol. Poin 8.3.4.

[6] Rini, Devina Candra Puspita \& Arifin, Khairul. (2020). Perencanaan Jumlah Gardu Pada Tol Pasuruan-Probolinggo. Jurnal Mahasiswa Teknik Sipil Universitas Brawijaya.

[7] Badan Pusat Statistik Jawa Timur, https://jatim.bps.go.id/publication.html 